\title{
BIPOLAR AND PSYCHOTIC DISORDERS IN ELITE ATHLETES: A NARRATIVE REVIEW
}

Corresponding author

Professor Alan Currie

Consultant Psychiatrist

Regional Affective Disorders Service

Northumberland Tyne and Wear NHS Foundation Trust

Wolfson Research Centre

Campus for Ageing and Vitality

Westgate Road

Newcastle

NE4 5PL

United Kingdom

alan.currie@ntw.nhs.uk

+441912468606

\section{Co-authors}

Dr. Paul Gorczynski

Senior Lecturer,

Department of Sport and Exercise Science,

University of Portsmouth,

Portsmouth,

United Kingdom

Dr. Simon Rice

Senior Research Fellow,

Orygen The National Centre of Excellence in Youth Mental Health, The University of Melbourne,

Australia

Dr. Rosemary Purcell

Associate Professor

Director, Research \& Translation 
Orygen, The National Centre of Excellence in Youth Mental Health, The University of Melbourne

Australia

Professor R. Hamish McAllister-Williams

Professor of Affective Disorders

Institute of Neuroscience

Newcastle University

United Kingdom

Mary E. Hitchcock

Senior Academic Librarian

Health Sciences Learning Centre

University of Wisconsin

Madison

Wisconsin

USA

Dr. Brian Hainline

NCAA Chief Medical Officer

Post Office Box 6222,

Indianapolis,

Indiana, USA 46206-6222

Dr. Claudia L. Reardon, M.D.

Associate Professor

Department of Psychiatry

University of Wisconsin School of Medicine and Public Health

Madison,

Wisconsin,

USA 
Word count (excluding title page, abstract, figures and tables) - 4308

\begin{abstract}
Bipolar and psychotic disorders are relatively common and likely to have a significant impact on quality of life and functioning which, in the context of elite sport, includes a potential negative impact on sporting performance. For this narrative review article, the literature on bipolar and psychotic disorders in elite athletes was comprehensively searched, and little relevant empirical research was found. A diagnosis of bipolar or psychotic disorders may be challenging in elite athletes because of complicating factors related to the modifying role of exercise and potential precipitating impact of substance use. Medications used to treat bipolar and psychotic disorders may have side effects particularly problematic for elite athletes. Future research should be tailored to the specific characteristics and needs of elite athletes and to the sporting context in which the disorders may arise. Specifically, further research is needed on the prevalence and incidence of these conditions in elite athletes and the impact of both the disorders and their treatments on sporting performance.
\end{abstract}

Keywords - psychiatry, disorder, sport, athlete, elite performance 


\section{INTRODUCTION}

The typical age of onset of bipolar and psychotic disorders coincides with average peak performance in elite athletes [1], yet information on their prevalence in elite athletes and their impact on athletic performance is limited. Furthermore, evidence to guide the clinician who is providing treatment for these conditions in elite athletes is primarily based on 'expert opinion' and extrapolation from general (non-sporting) guidelines.

The purposes of this narrative review are to: a) synthesise the literature on the diagnosis, prevalence, impact on performance, and management of bipolar and psychotic disorders in elite athletes; and b) provide recommendations based on what is currently known. One of the authors $(\mathrm{MH})$ searched key databases (PubMed, SportDiscus, PsycINFO, Scopus, and Cochrane) and repeated the searches in November 2018 (3 months before intended submission). Figure 1 illustrates the search strategy. Search terms relating to the disorders, sports participation, and the elite nature of participation were combined. We identified 420 potential references and included original studies that: a) were written in English; b) were conducted exclusively among current elite athletes; and c) presented information on bipolar or psychotic disorders. Twelve references were retained based on these inclusion criteria. These were then used by the other authors to identify related references. Other literature was also reviewed, where there were gaps in athlete-specific literature, for guidance on diagnosis, prevalence, functional impairment, and management. Elite athletes were defined as those competing at professional, Olympic, or collegiate/university levels. 
Figure 1. Search strategy

Terms relating to disorder

Psychotic Disorders; Affective Disorders, Psychotic; Bipolar,

Schizophrenia; Schizophrenic; Affective disorder, Personality disorder;

Psychotic; Manic-depressive; Psychotic disorder, Paranoia

\section{And $\downarrow$}

Terms relating to sport

Athlete; Athletic; Athletes; Sport

\section{And $\downarrow$}

Terms relating to elite nature of participation

Elite; Professional; Olympic; Highly trained; High performing; High performance; Competitive; Collegiate

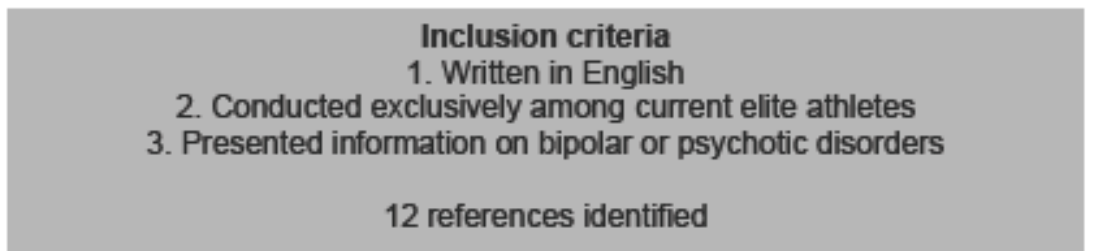

\section{Then $\downarrow$}

\section{Additional search 1}

All authors identify additional references cited in the 12 included studies

\section{Then $\downarrow$}

\section{Additional search 2}

Other literature where significant gaps in athlete specific literature

Figure 1. Search strategy 


\section{DIAGNOSIS OF BIPOLAR DISORDER}

Bipolar disorder is a recurrent and often chronic mental health disorder. It is characterised by episodes of elevated mood ('mania', or when less severe, 'hypomania') and also commonly of depressed mood, with associated change in functioning [2].

Mania is characterised by an abnormally and persistently elevated, expansive, or irritable mood and disinhibited behaviour [2]. Increased energy and reduced need for sleep are typical, and insight is frequently diminished. Psychotic symptoms such as delusions or hallucinations can occur, and if present, are usually consistent with the individual's elevated mood ('mood congruent'). Symptoms of mania must be present for at least 7 days and associated with significantly impaired function to permit diagnosis of a manic episode. Lesser degrees of functional impairment, or simply a change in functioning without impairment, for at least 4 days are consistent with a diagnosis of a hypomanic episode [2]. Episodes of mania and hypomania tend to be less frequent, and shorter, than depressive episodes [3,4].

Episodes of depression are characterised by some or all of the following: low mood; loss of interest or pleasure; reduced energy; changes in sleep and appetite; feelings of guilt or worthlessness; thoughts of death or suicide; psychomotor agitation or retardation; and poor concentration [2]. Symptoms can last for weeks or more. For diagnostic purposes, a minimum of 5 symptoms and duration of 2 weeks is specified for a major depressive episode. If psychotic symptoms are present, they are usually congruent with the individual's depressed mood.

Features of both hypomania or mania and depression can be concurrent (described as having 'mixed features') [2]. For example, an individual may exhibit increased activation and social disinhibition, but be dysphoric in mood. This combination may appear counterintuitive, but it is more common than often recognised [5]. Individuals in such states are at particularly high risk for suicide [6].

Two main specific subtypes of bipolar disorder are recognised [2]. In bipolar I disorder, there has been at least one manic episode (with or without episodes of 
major depression); in bipolar II disorder, hypomanic and major depressive episodes have occurred, with no periods of mania.

Patients with bipolar disorder (especially bipolar II disorder) may be misclassified as having a purely depressive illness [7]. Those with shorter hypomanic episodes and less functional impairment may not present for medical attention, and if no inquiry is made during assessment of a later depressive episode, the diagnosis may be missed.

\section{DIAGNOSIS OF PSYCHOTIC DISORDERS}

Psychotic disorders are characterised by symptoms such as hallucinations or delusions. In schizophrenia, additional symptoms are required to make the diagnosis, including some or all of the following: disorganised speech; grossly disorganised or catatonic behaviours; negative symptoms such as lack of motivation; and associated features such as inappropriate affect, cognitive deficits, and problems with social cognition. The diagnosis is only made if some symptoms have persisted for at least 6 months and significant functional impairment exists [2].

Other psychotic disorders are described and classified [2] and their features are summarised in Table 1. In delusional disorder, there is a narrower range of symptoms (primarily delusions). In brief psychotic disorder, the duration is shorter than in schizophrenia. In schizophreniform disorder, the duration is shorter and there is less functional impairment (often a provisional diagnosis). In schizoaffective disorder, mood symptoms occur alongside, and sometimes separate from, psychotic symptoms and may be primarily depressive or manic. Attenuated psychosis syndrome is not an official Diagnostic and Statistical Manual of Mental IIIness (DSM) diagnosis but is noted within the DSM as a Condition for Further Study [2], with manifestations that reportedly include delusions, hallucinations, or disorganised speech in attenuated (or sub-threshold) form but still sufficient to be distressing or disabling. A proportion of individuals with attenuated psychosis syndrome will progress to a full psychotic syndrome [8], even when symptoms appear to have resolved [9]. Individuals with attenuated psychosis syndrome are at risk for developing many non-psychotic disorders that may need treatment, particularly given their associations with suicidality $[10,11]$. 
Table 1. Schizophrenia and psychotic disorders

\begin{tabular}{|c|c|}
\hline Schizophrenia & $\begin{array}{l}\text { At least } 2 \text { of the following } 5 \text { features (at least } 1 \text { of which must be } 1 \text { of the first } \\
\text { 3): delusions; hallucinations; disorganised speech; marked behavioural } \\
\text { disturbance; negative symptoms such as diminished emotional expression or } \\
\text { avolition } \\
\text { Marked deterioration in functioning } \\
\text { Continuous signs of the disturbance for at least } 6 \text { moths } \\
\text { - Associated features may support the diagnosis: } \\
\text { - dysphoric mood with anxiety, anger, or depression } \\
\text { - cognitive deficits (which are strongly linked to functional impairments), e.g., in } \\
\text { memory, language, and executive functions } \\
\text { - deficits in social cognition, e.g., inability to infer the intentions of others }\end{array}$ \\
\hline Delusional Disorder & $\begin{array}{l}1 \text { or more delusions for at least } 1 \text { month } \\
\text { Hallucinations are not prominent and if present relate to the delusional theme (e.g., } \\
\text { sensations of insect infestation when delusions are of infestation) } \\
\text { Apart from the impact of the delusion(s) or its ramifications, functioning and behaviour } \\
\text { are not markedly impaired or bizarre }\end{array}$ \\
\hline $\begin{array}{l}\text { Brief Psychotic } \\
\text { Disorder }\end{array}$ & $\begin{array}{l}\text { Symptoms of at least } 1 \text { of the following: delusions; hallucinations; disorganised } \\
\text { speech; disorganised behaviour may or may not be present } \\
\text { Duration between } 1 \text { day and } 1 \text { month } \\
\text { Level of impairment may be severe but eventual return to full functioning } \\
\text { May occur in response to a severe stressor (and then sometimes called brief } \\
\text { reactive psychosis) }\end{array}$ \\
\hline $\begin{array}{l}\text { Schizophreniform } \\
\text { Disorder }\end{array}$ & $\begin{array}{l}\text { Characteristic symptoms identical to schizophrenia (at least } 2 \text { of } 5 \text { features, at } \\
\text { least } 1 \text { of which must be } 1 \text { of the first } 3 \text { ) } \\
\text { Shorter duration ( } 1 \text { to } 6 \text { months) } \\
\text { May be a provisional diagnosis, i.e., when the patient still has ongoing } \\
\text { symptoms but it has not yet been } 6 \text { months }\end{array}$ \\
\hline $\begin{array}{l}\text { Schizoaffective } \\
\text { Disorder }\end{array}$ & $\begin{array}{l}\text { An uninterrupted period of the illness during which there is a major mood } \\
\text { episode (major depressive or manic) concurrent with at least } 2 \text { of the } 5 \text { features of } \\
\text { schizophrenia } \\
\text { Delusions or hallucinations for } 2 \text { or more weeks in the absence of a major mood } \\
\text { episode during the lifetime of the illness } \\
\text { Symptoms meeting criteria for a major mood episode are present for the } \\
\text { majority of the total duration of the active and residual portions of the illness } \\
\text { Classified as bipolar type if any manic episodes have occurred and depressive } \\
\text { type if mood episodes have been exclusively depressive }\end{array}$ \\
\hline $\begin{array}{l}\text { Psychotic Disorder } \\
\text { Due to Another } \\
\text { Medical Condition }\end{array}$ & $\begin{array}{l}\text { Prominent delusions or hallucinations with significant distress or functional } \\
\text { impairment } \\
\text { Evidence via history, examination, or laboratory findings that symptoms are the } \\
\text { direct pathophysiological consequence of the medical condition } \\
\text { Symptoms not better explained by another mental disorder or by delirium }\end{array}$ \\
\hline $\begin{array}{l}\text { Substance/Medicat } \\
\text { ion-Induced } \\
\text { Psychotic Disorder }\end{array}$ & $\begin{array}{l}\text { Delusions and/or hallucinations with significant distress or functional impairment } \\
\text { Symptoms emerge during or soon after substance intoxication or withdrawal } \\
\text { (per evidence from history, examination, or laboratory findings) } \\
\text { The substance is known to be capable of producing delusions and/or } \\
\text { hallucinations } \\
\text { Symptoms not better explained by another psychotic disorder or by delirium }\end{array}$ \\
\hline $\begin{array}{l}\text { Attenuated } \\
\text { Psychosis } \\
\text { Syndrome }\end{array}$ & $\begin{array}{l}\text { Must have } 1 \text { of the following at least once per week for the past month: } \\
\text { delusions; hallucinations; disorganised speech } \\
\text { Symptoms are distressing and disabling }\end{array}$ \\
\hline
\end{tabular}


(included in the

DSM-5 as a

Condition for

Further Study)
Symptoms are below threshold for diagnosis of any other psychotic disorder (e.g., less severe and/or more transient)

[2]

\section{Secondary bipolar and psychotic disorders}

Substance/medication-induced bipolar disorder and bipolar disorder due to another medical condition are secondary bipolar disorders [2]. Similarly psychotic symptoms may also be substance/medication-induced or due to another medical condition [2]. Within the general population, some of these secondary disorders are more commonly a consideration when there is a later-age presentation [12] as they may be associated with conditions such as thyroid disease, multiple sclerosis, and rightsided cortical or subcortical brain lesions, which are commoner in older populations [13]. Of more relevance in sporting populations are traumatic brain injuries, where secondary bipolar disorder is a possible although uncommon sequela [14], and stimulant or anabolic androgenic steroid (AAS) use contributing to depressive or hypomanic symptoms, an unstable mood or psychotic symptoms [15-17].

\section{Sports-specific diagnostic issues}

A diagnosis of bipolar disorder or a psychotic disorder may be more difficult to make in an elite athlete. Exercise may be an outlet for the excess energy seen in mania or hypomania, which could delay diagnosis. In addition, over-activity may be obscured or normalised in the context of athletic training [18]. AAS may be misused by athletes for performance reasons $[16,19]$; the mood disturbance and psychotic symptoms that have been reported in association with their use can confuse diagnosis. Importantly, though, hypomanic symptoms secondary to AAS are usually sub-syndromal and typically only seen when high doses of multiple agents are used (often called 'stacking') [17,20]. Depressive symptoms have been described among athletes withdrawing from AAS use $[17,20]$. Again, there is an association between high dosages and 'stacking' and depression [20,21]. However, many studies of this topic had small sample sizes, no control groups, multiple potential confounders, and cross-sectional designs. Other substances used by some athletes - including 
stimulants, cannabis, and glucocorticoids - may be associated with psychotic symptoms $[16,19]$. It is important to distinguish primary mood and psychotic disorders from substance-induced forms, as the latter may be self-limiting or require only short-term treatment [21]. A comprehensive history - supplemented by appropriate urine testing and toxicology - is necessary to confirm the diagnosis [22]. Table 2 provides a list of features that may help distinguish between primary bipolar and psychotic disorders and those secondary to substance misuse by elite athletes.

Table 2. Features that may help distinguish between primary bipolar and psychotic disorders and those secondary to substance misuse in sport.

\begin{tabular}{|c|c|c|}
\hline & Primary disorder & Secondary to substance use \\
\hline History & $\begin{array}{l}\text {-Possible past history of } \\
\text { episodes } \\
\text { - Family history of disorder } \\
\text { - No report of substance use }\end{array}$ & $\begin{array}{l}\text {-Use may be acknowledged } \\
\text { with sensitive enquiry and } \\
\text { corroborative reports (e.g., } \\
\text { from family, friends, etc.). }\end{array}$ \\
\hline Clinical features & $\begin{array}{l}\text { - Symptoms may be similar. } \\
\text { - Longitudinal course is more } \\
\text { likely to be of episodes } \\
\text { lasting weeks or more. }\end{array}$ & $\begin{array}{l}\text { - Symptoms may be similar. } \\
\text { Episodes may self-limit after } \\
\text { a few days. } \\
\text { - Irritability and aggression are } \\
\text { more common. } \\
\text { - Sub-syndromal presentations } \\
\text { are more likely than full } \\
\text { syndromes. } \\
\text { - Close temporal relationship } \\
\text { to use } \\
\text { - Association with high-dose } \\
\text { and multiple substance use }\end{array}$ \\
\hline Physical exam & $\begin{array}{l}\text { Signs of increased arousal may } \\
\text { be present (e.g., increased } \\
\text { pulse and/or blood pressure). }\end{array}$ & $\begin{array}{l}\text { The following signs may be } \\
\text { present: } \\
\text { - AAS use - acne, needle } \\
\text { marks, female hirsutism, } \\
\text { jaundice, gynaecomastia } \\
\text { (males), breast atrophy } \\
\text { (females), testicular atrophy } \\
\text { or prostatic hypertrophy } \\
\text { (males), clitiromegaly } \\
\text { (females) } \\
\text { - } \\
\text { Stimulant use - increased } \\
\text { arousal, dilated pupils, tics } \\
\text { Cannabinoid use - } \\
\text { characteristic smell, } \\
\text { conjunctival injection, } \\
\text { drowsy, slowed responses, } \\
\text { impaired short-term memory }\end{array}$ \\
\hline
\end{tabular}

[17,19-22] 


\section{ASSESSMENT}

For an elite athlete who may have bipolar disorder, the standard assessment begins with a detailed history of mood episodes, triggers, and symptoms between episodes, with corroboration from a family member or other close informants if possible [23]. A detailed history includes all medications (and any supplements or ergogenic aids) and will help to diagnose common comorbidities such as anxiety disorders and other conditions that may confound the diagnosis. These include personality disorders, attention-deficit/ hyperactivity disorder (ADHD), illicit or prescribed drug use or use disorders, and medical conditions associated with secondary mania or secondary psychosis $[13,23,24]$.

The role of exercise in an athlete's symptoms needs to be considered when assessing for bipolar disorder. Less frequent exercise is often associated with depression, and more frequent exercise with mania [25]; the amount of exercise may be a manifestation of the disorder.

Bipolar disorder is unusual compared to other mental health disorders in that regular exercise does not seem to offer a protective effect. In a large prospective community survey, the incidence of bipolar disorder over a 4-year period was greater in those with regular physical activity at baseline [26]. Furthermore, although some bipolar patients report that exercise is helpful in mood regulation, directing energy and bringing structure to activities, others report that it contributes to spiralling of hypomanic and manic symptoms [27]. The type of sport and the nature of the physical activity may be relevant. Rhythmic sporting activities (e.g., running, walking, and swimming) may be calming and facilitate mood regulation [27]. Conversely, participants in extreme or high-risk sports (e.g., mountain biking or rock climbing) report high scores on measures of bipolar symptoms [28].

When considering the role of exercise in the development of hypomanic and manic symptoms, some possible mechanisms have been described. Exercise and antidepressant medication may share similar biological mechanisms [29] and thus 
may induce hypomania and mania in patients with bipolar disorder [30]. In addition neurobiological systems involved in goal striving and reward seeking (principally dopaminergic projections) may be dysregulated in those with bipolar disorder [31]. This may explain underlying biological vulnerability as well as the course of the disorder via triggers which dysregulate these systems [32]. Of relevance in performance sport is that when there is an underlying vulnerability then sporting activity via goal striving, reward seeking and goal attainment could act as a trigger for manic or hypomanic symptoms [32].

In the assessment process, it therefore may be necessary to consider whether sporting activity is a manifestation of the underlying disorder, a helpful way of managing symptoms, or a contributory factor to mood instability and especially to hypomania and mania.

Psychotic symptoms are experienced by $5-8 \%$ of the general population [33] and $7.5 \%$ of 13-18 year olds [10]. Since these symptoms do not necessarily predict overt psychotic disorders, careful assessment is warranted. The self-administered 16-item Prodromal Questionnaire (PQ16) [34] may be a useful screening tool for psychotic disorders (Table 3). The respondent indicates for each item whether this experience is 'True or False' and indicates how much distress is associated with each 'True' item, on a Likert scale of 0-3. A score is determined by summing the number of items endorsed as 'True'. A score of 6 or more has optimal sensitivity (87\%) and specificity $(87 \%)$ [34] and indicates the respondent may be at risk for psychosis. Athletes who meet this cut-off, or who otherwise disclose concerns about psychotic-like symptoms, should be referred to specialist mental health services for a more detailed clinical history [35]. There are no sports-specific psychosis screening tools.

Table 3. The 16-item version of the Prodromal Questionnaire (PQ-16) by permission of the Oxford University Press.

\begin{tabular}{|l|l|l|}
\hline & & $\begin{array}{l}\text { If TRUE: how much distress did you } \\
\text { experience? }\end{array}$ \\
\hline & & None Mild Moderate Severe \\
\hline
\end{tabular}




\begin{tabular}{|c|c|c|c|c|c|}
\hline $\begin{array}{l}\text { 1. I feel uninterested in the things I used to } \\
\text { enjoy. }\end{array}$ & $\square$ True & $\square$ False & $\begin{array}{l}\square 1 \\
\square 4\end{array}$ & $\square 2$ & $\square 3$ \\
\hline $\begin{array}{l}\text { 2. I often seem to live through events exactly } \\
\text { as they happened before (déjà vu). }\end{array}$ & $\square$ True & $\square$ False & $\begin{array}{l}\square 1 \\
\square 4\end{array}$ & $\square 2$ & $\square 3$ \\
\hline $\begin{array}{l}\text { 3. I sometimes smell or taste things that } \\
\text { other people can't smell or taste. }\end{array}$ & $\square$ True & $\square$ False & $\begin{array}{l}\square 1 \\
\square 4\end{array}$ & $\square 2$ & $\square 3$ \\
\hline $\begin{array}{l}\text { 4. I often hear unusual sounds like banging, } \\
\text { clicking, hissing, clapping or ringing in my } \\
\text { ears. }\end{array}$ & $\square$ True & $\square$ False & $\begin{array}{l}\square 1 \\
\square 4\end{array}$ & $\square 2$ & $\square 3$ \\
\hline $\begin{array}{l}\text { 5. I have been confused at times whether } \\
\text { something I experienced was real or } \\
\text { imaginary. }\end{array}$ & $\square$ True & $\square$ False & $\begin{array}{l}\square 1 \\
\square 4\end{array}$ & $\square 2$ & $\square 3$ \\
\hline $\begin{array}{l}\text { 6. When I look at a person, or look at myself } \\
\text { in a mirror, I have seen the face change right } \\
\text { before my eyes. }\end{array}$ & $\square$ True & $\square$ False & $\begin{array}{l}\square 1 \\
\square 4\end{array}$ & $\square 2$ & $\square 3$ \\
\hline $\begin{array}{l}\text { 7. I get extremely anxious when meeting } \\
\text { people for the first time. }\end{array}$ & $\square$ True & $\square$ False & $\begin{array}{l}\square 1 \\
\square 4\end{array}$ & $\square 2$ & $\square 3$ \\
\hline $\begin{array}{l}\text { 8. I have seen things that other people } \\
\text { apparently can't see. }\end{array}$ & $\square$ True & $\square$ False & $\begin{array}{l}\square 1 \\
\square 4\end{array}$ & $\square 2$ & $\square 3$ \\
\hline $\begin{array}{l}\text { 9. My thoughts are sometimes so strong that } \\
\text { I can almost hear them. }\end{array}$ & $\square$ True & $\square$ False & $\begin{array}{l}\square 1 \\
\square 4\end{array}$ & $\square 2$ & $\square 3$ \\
\hline $\begin{array}{l}\text { 10. I sometimes see special meanings in } \\
\text { advertisements, shop windows, or in the way } \\
\text { things are arranged around me. }\end{array}$ & $\square$ True & $\square$ False & $\begin{array}{l}\square 1 \\
\square 4\end{array}$ & $\square 2$ & $\square 3$ \\
\hline $\begin{array}{l}\text { 11. Sometimes I have felt that I'm not in } \\
\text { control of my own ideas or thoughts. }\end{array}$ & $\square$ True & $\square$ False & $\begin{array}{l}\square 1 \\
\square 4\end{array}$ & $\square 2$ & $\square 3$ \\
\hline $\begin{array}{l}\text { 12. Sometimes I feel suddenly distracted by } \\
\text { distant sounds that I am not normally aware } \\
\text { of. }\end{array}$ & $\square$ True & $\square$ False & $\begin{array}{l}\square 1 \\
\square 4\end{array}$ & $\square 2$ & $\square 3$ \\
\hline $\begin{array}{l}\text { 13. I have heard things other people can't } \\
\text { hear like voices of people whispering or } \\
\text { talking. }\end{array}$ & $\square$ True & $\square$ False & $\begin{array}{l}\square 1 \\
\square 4\end{array}$ & $\square 2$ & $\square 3$ \\
\hline 14. I often feel that others have it in for me. & $\square$ True & $\square$ False & $\begin{array}{l}\square 1 \\
\square 4\end{array}$ & $\square 2$ & $\square 3$ \\
\hline $\begin{array}{l}\text { 15. I have had the sense that some person or } \\
\text { force is around me, even though I could not } \\
\text { see anyone. }\end{array}$ & $\square$ True & $\square$ False & $\begin{array}{l}\square 1 \\
\square 4\end{array}$ & $\square 2$ & $\square 3$ \\
\hline $\begin{array}{l}\text { 16. I feel that parts of my body have changed } \\
\text { in some way, or that parts of my body are } \\
\text { working differently than before. }\end{array}$ & $\square$ True & $\square$ False & $\begin{array}{l}\square 1 \\
\square 4\end{array}$ & $\square 2$ & $\square 3$ \\
\hline
\end{tabular}

If a psychotic disorder is suspected for the first time, rapid assessment by a specialist mental health services is indicated [35]. The assessment should include a careful evaluation of symptoms, a psychosocial assessment, and a risk assessment $[35,36]$. Conditions that can cause secondary psychosis (e.g., substance use disorders) should also be investigated as indicated. If medication is required, then 
medication choice will be influenced by both comorbid medical conditions such as renal or hepatic disease and by anticipated side effects such as dyslipidaemias, impaired glucose tolerance, hyperprolactinaemia, and QTc prolongation. For these reasons, preliminary investigations often include renal and liver function tests, a metabolic profile (height, weight, blood pressure, and lipid and glucose profiles), prolactin levels, and an electrocardiogram [36].

\section{PREVALENCE}

The lifetime prevalence of bipolar disorder in the general population is approximately $0.4 \%$ for type I and $0.6 \%$ for type II; sub-threshold symptoms are more common, at around $1.4 \%$ [37]. Lifetime prevalence of schizophrenia and related disorders is thought to be around $0.5 \%$, but with regional variations [38]. To date, there are no reliable prevalence data on either bipolar or psychotic disorders in elite athletes [3941]. However, schizophrenia seems to be under-represented in elite athletes [42]. The late teens and early twenties are the peak age of performance in many sports, and close to the peak age of onset of conditions such as bipolar and psychotic disorders [1]. Thus, it would be expected that elite athletes could present with either condition, if only by coincidence.

\section{IMPACT ON PERFORMANCE}

Case reports of high-profile athletes with bipolar disorder indicate that the condition is not incompatible with sporting success [43]. In addition, bipolar disorder is episodic, with relatively euthymic periods in between symptomatic episodes [3,4]. When hypomanic, an athlete's training might not be unduly compromised, and functional impairment is not always found at this stage [2]. However, as symptoms increase, concentration, decision-making, and organisation are affected with associated functional impairments including difficulty participating in sport, exercise, and physical activity [44]. Vigorous exercise may even precipitate or perpetuate mania in bipolar disorder [45], such that elite athletes with bipolar disorder may be limited in the maximum amount of exercise they can safely undertake without risk of mood destabilisation. This situation can be problematic when insight becomes impaired, as it often does in emerging mania, and individuals may be reluctant to respond to advice to change behaviours and activity patterns because they perceive no need to do so. 
Although bipolar disorder is an episodic illness, individuals can expect to spend significant amounts of time in a symptomatic state. In one survey over an average of 12.8 years, those with bipolar I disorder spent $47.3 \%$ of the time experiencing symptoms. Depressive symptoms were the commonest ( $39 \%$ of the time) but were often sub-syndromal [4]. A similar survey reported that individuals with bipolar II disorder were symptomatic $53.9 \%$ of the time, over an average of 13.4 years, with depressive symptoms the commonest (50.3\% of the time) [3].

Approximately $40 \%$ of people with bipolar disorder have some associated cognitive impairment [46]. All cognitive domains are affected (including attention, executive function, and memory), even when mood symptoms are relatively absent [47]. The severity of impairment seems greatest in those suffering from type I bipolar disorder and in those with psychotic symptoms [48], but in general is not as problematic as in schizophrenia [49]. There is promise that early initiation of effective treatments may prevent or attenuate cognitive deficits [50].

Symptoms in schizophrenia (and related psychoses) are often grouped into five domains, as illustrated in Figure 1. Although some people with schizophrenia can expect a good outcome, a significant number will experience a more chronic and pervasive course with a resultant impact on sporting, academic, employment, and social function. Symptoms in the cognitive and negative domains are primarily associated with functional impairment $[51,52]$. Longer-term symptoms in the negative domain, especially avolition and amotivation (lack of initiative for purposeful tasks), may negatively impact significantly on commitment and ability to sustain elite-level sports participation. Difficulties with executive function and working memory would be expected to impair ability to pursue most activities requiring processing speed and complex execution, including elite sports performance. Schizophrenia is thus likely to interfere with the demands of elite athletes for both training and competition. That this condition appears to be under-represented among elite athletes may relate to these issues [42].

Figure 2. Symptom domains in schizophrenia 


\section{MANAGEMENT}

Delayed treatment of bipolar disorder [53] and long-standing untreated psychosis [54] both correlate with a worse outcome.

Clinical staging [55] offers a longitudinal perspective of bipolar and psychotic disorders, from an at-risk state (i.e., no symptoms), through attenuated or subthreshold syndromes, to first and potentially subsequent episodes. In sub-threshold stages, psychological interventions and regular monitoring are recommended [56], Mood stabilising or antipsychotic medication is typically reserved for the first episode of a diagnosed disorder, given the side effect profile of these medications [57].

\section{Exercise and Psychotherapy interventions}

Although individuals with bipolar and psychotic disorders may have difficulties sustaining high-level sport performance, there are potential benefits to continuing recreational exercise and sport. Adolescent athletes report multiple mental health benefits of sports participation, especially in team sports [58]. Moderate levels of physical activity may also benefit symptoms of bipolar and psychotic disorders $[45,59,60]$, although there remains a relative lack of research on the relationships between high volume and high-intensity athletic training and symptoms of bipolar disorder or psychosis. Exercise can help former athletes diagnosed with psychosis to establish a new sense of self and purpose in recovery [61]. Maintaining activities contributes to the experience of recovery that includes finding meaning in and developing a sense of agency, identity, and engagement with life [62]. Many individuals experiencing psychotic disorders encounter challenges with relationships and broader social inclusion; in such cases, physical activity and sports participation can help individuals sustain functioning [63].

Hippocampal volume is lower than expected in individuals diagnosed with either bipolar disorder or schizophrenia [64], but can be increased by exercise in both patients and healthy controls, with associated improvements in cognitive function [65]. Exercise may also improve neuroplasticity and promote neurogenesis in affected individuals; in addition, cardiorespiratory fitness may attenuate the changes in brain volume among those with schizophrenia [66]. However, it is unknown if improved cognitive function or degree of attenuation can prevent illness progression 
so that an athlete could sustain an elite level of performance. Exercise may also reduce disrupted circadian rhythm and sleep patterns [67] in both schizophrenia [68] and bipolar disorder [69]. At present, exercise and physical activity do not feature in the practice guidance for either bipolar disorder or schizophrenia in the United Kingdom or United States $[23,24,35,36]$.

Psychoeducation is recommended for bipolar disorder [23,24], and has the best evidence among all psychotherapy interventions for bipolar disorder within the general population [70]. Educational components include information on the nature of the illness, factors that can cause destabilisation, use of long-term medications, and the appropriate use of short-term medications and other strategies to address early signs of relapse. Interpersonal social rhythms therapy also reportedly sustains function in bipolar disorder [71,72]. Other psychotherapy interventions that may be useful in bipolar disorder include cognitive behavioural therapy, interpersonal psychotherapy for bipolar depressive symptoms, and family interventions, although much of the evidence is extrapolated from patients with unipolar depression $[23,24]$ and none is specific to elite athletes.

Psychotherapy interventions such as cognitive behavioural therapy and family interventions are also recommended for psychotic disorders [35,36], but again there is no sports-specific evidence on which to base such treatment in athletes. While family psychoeducation has fairly strong evidence for schizophrenia, that this intervention often consists of regularly occurring group meetings may be incompatible with elite athletes' travel schedules and desire for confidentiality.

\section{Medication management}

There is limited evidence regarding medication treatment of bipolar disorder and psychotic conditions in athletes [39-41]; guidance comes primarily from extrapolation from general population recommendations, and from expert opinion regarding athlete prescribing. Overall, an approach of 'carefully considered individual prescribing' is recommended [73]. One important element of this is to consider the potential negative impact of medication side effects on athletic performance [73,74]. This is accompanied by the need to understand the impact of an athlete's physiological 
stressors on both pharmacodynamics (the effect of the drug on the athlete) and pharmacokinetics (how the athlete's body handles the drug) [73,74].

Guidance for the treatment of bipolar disorder needs to address acute mania/hypomania, acute depression, mood episodes with mixed features, and longterm prophylactic treatment to minimise recurrence [13,23,24]. During acute mania, antipsychotics can have a rapid anti-manic effect and may be augmented with shortterm benzodiazepines [13,23,24]. First- (e.g., haloperidol) and second- (e.g., aripiprazole, lurasidone, olanzapine, quetiapine, risperidone, ziprasidone) generation antipsychotics can be used, with some guidance for the general population preferring second-generation drugs [24]. Aripiprazole is recommended as the first choice in the general adolescent population because of its more favourable metabolic profile [23], which may be a consideration relevant to elite athletes as well. In those with less severe mania, monotherapy with valproate or lithium can be considered [24], although valproate should typically not be used in women of childbearing age, an age group into which most elite women athletes fall. For those who relapse while prescribed medication, it is helpful to begin by assessing treatment adherence and optimising existing treatments (e.g., by checking lithium or valproate blood levels and increasing dosages if necessary) [13,23,24]. When mixed features are present, guidance suggests following treatment as for acute mania [13].

In the depressive phase of bipolar disorder, optimising existing treatments is also recommended [13,24]. Quetiapine, lurasidone, or olanzapine plus fluoxetine are particularly evidence-based choices in the general population [13]. Lamotrigine also has efficacy [75], but requires slow titration over weeks. The evidence for lithium is more equivocal in acute treatment, but it is recommended if there is previous evidence of effectiveness [13], and it is more likely to be efficacious when combined with lamotrigine [76]. Antidepressants have generally not been proven effective in treating bipolar depression [77]. If an antidepressant is used, some individuals appear to respond to selective serotonin reuptake inhibitors (SSRIs), which appear to be less likely to cause a switch into mania than serotonin and norepinephrine reuptake inhibitors (SNRIs) [78] and tricyclic antidepressants [79] Regardless, antidepressants should be used cautiously and typically only in combination with a long-term anti-manic treatment, especially for individuals with bipolar I disorder [13]. 
For prophylaxis of future mood episodes in bipolar disorder within the general population, lithium is a usual first-line treatment and has efficacy in preventing relapse into either mania or depression [13,23,24]. Quetiapine may reduce long-term depressive and manic relapses [80]. Lamotrigine is more effective at preventing depressive relapses, while valproate and antipsychotics such as aripiprazole, lurasidone, olanzapine, and risperidone are more effective for preventing manic relapses $[13,23]$.

Data on medication recommendations specifically for athletes with bipolar disorder are largely limited to expert opinion. Lithium and lamotrigine can be used by athletes, and sports psychiatrists have expressed preferences for these two drugs [81]. Lithium has a narrow therapeutic window and requires careful monitoring, especially in athletes [73]. Data on impact of exercise on lithium levels are preliminary and mixed. Sweat loss may lower lithium levels below therapeutic levels $[82,83]$, but there is also concern that dehydration may raise levels towards toxicity [74]. Lamotrigine, unlike many other medication options, does not cause weight gain and might be chosen for this reason [73,81]. Among the second-generation (atypical) antipsychotics, aripiprazole, lurasidone, and ziprasidone may be relatively less likely to cause sedation and weight gain, often considered problematic for athletes $[73,81]$. Ziprasidone may cause QTc prolongation [84] and thus may not be a first-line choice within this class for elite athletes [81]. Quetiapine can be considered but is sedating for many, and aripiprazole may cause akathisia, which could negatively impact motor function and elite sporting performance [73].

Within the general population, the mainstay of pharmacological treatment in an established and sustained psychotic illness is either first- or second-generation antipsychotic medication, with clozapine reserved for treatment-resistant cases $[35,36,85]$. Some guidance suggests choosing a drug based on the side effect profile, noting that first- and second-generation drugs are broadly equal in efficacy $[35,85]$. Other guidance recommends using second-generation antipsychotics preferentially unless there has been a good previous response to a first-generation drug [36]. 
When offering treatment for athletes with psychosis, guidance again comes primarily from expert opinion. First-generation (typical) antipsychotics are an infrequent choice because of sedation, motor side effects, and cardiac concerns [81] and the considerations when choosing a second generation drug are similar to those described above in relation to bipolar disorder.

No pharmacological treatments approved for either bipolar or psychotic disorders require a Therapeutic Use Exemption (TUE). On occasion, beta-blockers have been used to manage tremor as a side effect of lithium therapy or akathisia as a side effect of antipsychotics; a TUE would be required for this treatment in certain sports and situations [86]. Possible pharmacological treatments for athletes are summarised in Table 4.

Table 4. 'Sports specific' medication options in bipolar disorder and psychosis

\begin{tabular}{|c|c|c|c|c|}
\hline & Bipolar mania & $\begin{array}{l}\text { Bipolar } \\
\text { depression }\end{array}$ & $\begin{array}{l}\text { Bipolar } \\
\text { prophylaxis }\end{array}$ & Psychosis \\
\hline $\begin{array}{l}\text { 'Expert } \\
\text { opinion' } \\
{[73]}\end{array}$ & $\begin{array}{l}\text {-Aripiprazole } \\
\text { (but akathisia) } \\
\text {-Quetiapine (but } \\
\text { sedating) }\end{array}$ & $\begin{array}{l}\text { - Lamotrigine } \\
\text {-Quetiapine (but } \\
\text { sedating) }\end{array}$ & $\begin{array}{l}\text { - Lithium (both } \\
\text { poles but careful } \\
\text { monitoring) } \\
\text { - Lamotrigine } \\
\text {-Aripiprazole (but } \\
\text { akathisia) } \\
\text {-Quetiapine (but } \\
\text { sedating) }\end{array}$ & $\begin{array}{l}\text {-Aripiprazole } \\
\text { (but akathisia) } \\
\text {-Quetiapine } \\
\text { (but sedating) }\end{array}$ \\
\hline $\begin{array}{l}\text { 'Expert } \\
\text { opinion' } \\
{[74]}\end{array}$ & $\begin{array}{l}\text {-Aripiprazole or } \\
\text { - Lurasidone } \\
\text { (Both less } \\
\text { sedating and } \\
\text { fewer metabolic } \\
\text { or cardiac } \\
\text { concerns) }\end{array}$ & $\begin{array}{l}\text { - Lamotrigine } \\
\text { - Lurasidone } \\
\text { (Less sedating } \\
\text { and fewer } \\
\text { metabolic or } \\
\text { cardiac concerns) }\end{array}$ & $\begin{array}{l}\text { - Lamotrigine } \\
\text { - Lithium (with } \\
\text { careful } \\
\text { monitoring) } \\
\text {-Aripiprazole or } \\
\text { - Lurasidone } \\
\text { (Both less } \\
\text { sedating and } \\
\text { fewer metabolic } \\
\text { or cardiac } \\
\text { concerns) }\end{array}$ & $\begin{array}{l}\text {-Aripiprazole or } \\
\text { - Lurasidone } \\
\text { (Both less } \\
\text { sedating and } \\
\text { fewer metabolic } \\
\text { or cardiac } \\
\text { concerns) }\end{array}$ \\
\hline
\end{tabular}




\begin{tabular}{|l|l|l|l|l|}
\hline $\begin{array}{l}\text { Preference } \\
\text { of sports } \\
\text { psychiatrists }\end{array}$ & $\begin{array}{l}\bullet \text { Aripiprazole or } \\
\text { [81] }\end{array}$ & $\begin{array}{l}\bullet \text { Lamotrigine } \\
\bullet \text { Lurasidone }\end{array}$ & $\begin{array}{l}\bullet \text { Lamotrigine } \\
\bullet \text { Lithium }\end{array}$ & $\begin{array}{l}\bullet \text { Aripiprazole or } \\
\bullet \text { Lurasidone } \\
\text { (Both less }\end{array}$ \\
& & & $\begin{array}{l}\text {-Aripiprazole } \\
\text {-Lurasidone }\end{array}$ & $\begin{array}{l}\text { sedating and } \\
\text { fewer metabolic } \\
\text { or cardiac } \\
\text { concerns) }\end{array}$ \\
\hline
\end{tabular}

$[73,74,81]$

\section{SUMMARY}

Bipolar and psychotic disorders can have a significant negative impact on individuals in the general population, but the prevalence of these disorders among elite athletes is unknown. Cross-sectional studies to identify those with bipolar or psychotic disorder diagnoses are needed, as are methodologically more robust studies describing relationships between performance-enhancing substances and mental health symptoms and disorders. Information on particular symptom manifestations within sporting populations and population specific screening tools would be especially useful. Although accurate prevalence data on bipolar and psychotic disorders in elite athletes are lacking, those who practice in sport require at least a basic knowledge of these conditions to ensure early identification and facilitate access to treatment, and thus improve outcomes.

Bipolar and psychotic disorders can be chronic and/or relapsing conditions where medication is recommended to restore and sustain health. Although psychotherapy interventions are usually recommended, these non-pharmacological strategies are generally in addition to medications rather than as alternatives. This is unlike treatments for anxiety disorders and mild or moderate depression, where psychotherapy may be an evidence-based alternative, and in attenuated psychosis syndrome, where psychotherapy used without medication may prevent symptom progression. The absence of athlete-specific medication trials is therefore of particular importance. High-quality data on uses of medication at the extremes of human physiology (i.e., during intense exercise) and on the performance impact of 
commonly prescribed medications for bipolar or psychotic disorders are needed. At present, prescribers must rely on expert opinion, using information extrapolated from general population studies and taking into account the athlete's physiology and the demands of each sport.

Finally, both physical activity and sports participation can have multiple benefits for individuals with bipolar or psychotic disorders. Mental health service providers can ally with the world of sport, exercise, and fitness for the benefit of patients and to help improve outcomes for conditions that can be chronic and relapsing. This includes athletes whose illnesses impair their progress and who could be encouraged to maintain activities and, if necessary, given a supported exit strategy from elite-level sport to a lower or more recreational level of activity. 


\section{ACKNOWLEDGEMENTS}

The authors thank the other participants in the 2018 International Olympic

Committee Consensus Meeting on Mental Health in Elite Athletes, including Cindy Miller Aron, David Baron, Antonia Baum, Abhinav Bindra, Richard Budgett, Niccolo Campriani, Joao Mauricio Castaldelli-Maia, Jeff Derevensky, Lars Engebretsen, Ira Glick, Vincent Gouttebarge, Michael Grandner, Doug Hyun Han, David McDuff, Margo Mountjoy, Aslihan Polat, Margot Putukian, Allen Sills, Torbjorn Soligard, Todd Stull, Leslie Swartz, and Li Jing Zhu, for their input on the development and interpretation of this research.

\section{COMPETING INTERESTS}

Prof. McAllister-Williams reports personal fees in the last 3 years from Sunovion, Janssen, My Tomorrows, Lundbeck, Pfizer, LivaNova, Syntropharma, OCM Comunicaziona s.n.c., American Center for Psychiatry \& Neurology (United Arab Emirates), Qatar International Mental Health Conference, British Association for Psychopharmacology, European College of Neuropsychopharmacology, UK Medical Research Council, International Society for Affective Disorders and Wiley. He has received non-financial support from COMPASS and grants from research related to psychotropic drugs from the UK National Institute for Health Research. 


\section{BULLET POINTS}

\section{What is currently known?}

-Bipolar and psychotic disorder symptoms may be primary, a result of substance/medication use, or a result of other medical conditions.

-Bipolar and psychotic disorders often have a significantly negative impact on functioning and quality of life.

-Individuals with bipolar and psychotic disorders may benefit from early treatment.

-Bipolar and psychotic disorders are typically chronic in nature and generally require long-term medication management alongside psychotherapy interventions.

\section{What are the new findings?}

-A diagnosis of bipolar or psychotic disorders may be more difficult to make in an elite athlete because of complicating factors related to the modifying role of exercise and potential precipitating impact of substance use.

-Symptoms of bipolar and psychotic disorders may have a negative impact on sport performance and may often be incompatible with elite level sport participation, though there may be an important role for continued exercise at lower levels of participation even if elite-level competition is not possible.

-Medications used to treat bipolar and psychotic disorders may have many sideeffects particularly problematic for elite athletes, though there is a need for more study of pharmacological options within this population.

-More research is needed on the incidence and prevalence of bipolar and psychotic disorders within elite athletes, particular symptom 


\section{REFERENCES}

1 Moesch K, Kenttä G, Kleinert J, et al. FEPSAC position statement: Mental health disorders in elite athletes and models of service provision. Psychol Sport Exerc 2018;38:61-71. doi:10.1016/J.PSYCHSPORT.2018.05.013

2 American Psychiatric Association. Diagnostic and Statistical Manual of Mental Disorders (DSM-5). 5th ed. Washington, DC: : American Psychiatric Publishing 2013. https://www.appi.org/Course/Book/Subscription/JournalSubscription/id3322/Diagnostic_and_Statistical_Manual_of_Mental_Disorders_\%28DSM$5 \circledR \% 29$ (accessed 29 Jun 2018).

3 Judd LL, Akiskal HS, Schettler PJ, et al. A prospective investigation of the natural history of the long-term weekly symptomatic status of bipolar II disorder. Arch Gen Psychiatry 2003;60:2619.http://www.ncbi.nlm.nih.gov/pubmed/12622659 (accessed 4 Aug 2018). Judd LL, Akiskal HS, Schettler PJ, et al. The long-term natural history of the weekly symptomatic status of bipolar I disorder. Arch Gen Psychiatry 2002;59:530-7.http://www.ncbi.nlm.nih.gov/pubmed/12044195 (accessed 4 Aug 2018).

5 Goldberg JF, Perlis RH, Bowden CL, et al. Manic Symptoms During Depressive Episodes in 1,380 Patients With Bipolar Disorder: Findings From the STEP-BD. 2009. http://edengalaxy.com/images/PDFs/111-bipolar-expertspecialist-manic-psychotherapist-psychologist.pdf (accessed 9 Jan 2019). Swann AC, Lafer B, Perugi G, et al. Bipolar Mixed States: An International Society for Bipolar Disorders Task Force Report of Symptom Structure, Course of Illness, and Diagnosis. Am J Psychiatry 2013;170:31-42. doi:10.1176/appi.ajp.2012.12030301

7 Hantouche EG, Akiskal HS, Lancrenon S, et al. Systematic clinical methodology for validating bipolar-II disorder: data in mid-stream from a French national multi-site study (EPIDEP). J Affect Disord 1998;50:16373.http://www.ncbi.nlm.nih.gov/pubmed/9858076 (accessed 20 Apr 2018).

8 Tsuang MT, Van Os J, Tandon R, et al. Attenuated psychosis syndrome in DSM-5. Schizophr Res 2013;150:31-5. doi:10.1016/j.schres.2013.05.004

9 Rice SM, McGorry PD, Amminger GP, et al. Current versus recently resolved attenuated psychotic symptoms: Same level of risk for transition to psychosis? 
Schizophr Res 2018;:9-10. doi:10.1016/j.schres.2018.09.023

10 Kelleher I, Connor D, Clarke MC, et al. Prevalence of psychotic symptoms in childhood and adolescence: a systematic review and meta-analysis of population-based studies. Psychol Med 2012;42:1857-63. doi:10.1017/S0033291711002960

11 Lin A, Wood SJ, Nelson B, et al. Outcomes of Nontransitioned Cases in a Sample at Ultra-High Risk for Psychosis. Am J Psychiatry 2015;172:249-58. doi:10.1176/appi.ajp.2014.13030418

12 Khan H, Sami M, Nilforooshan R. Late onset mania as an organic illness - a review of case reports. J Neurol Neurosurg Psychiatry 2016;87:e1. doi:10.1136/jnnp-2016-315106.212

13 Goodwin GM, Haddad PM, Ferrier IN, et al. Evidence-based guidelines for treating bipolar disorder: Revised third edition recommendations from the British Association for Psychopharmacology. J Psychopharmacol 2016;30:495-553. doi:10.1177/0269881116636545

14 Silver JM, Kramer R, Greenwald S, et al. The association between head injuries and psychiatric disorders: Findings from the New Haven NIMH Epidemiologic Catchment Area Study. Brain Inj 2001;15:935-45. doi:10.1080/02699050110065295

15 Creado S, Reardon C. The sports psychiatrist and performance-enhancing drugs. Int Rev Psychiatry 2016;28:564-71.

doi:10.1080/09540261.2016.1190690

16 Baron DA, Reardon CL, Baron SH. Doping in Sport. In: Baron DA, Reardon CL, Baron SH, eds. Clinical Sports Psychiatry: An International Perspective. Oxford: : John Wiley \& Sons 2013. 21-32. doi:10.1002/9781118404904.ch3

17 Piacentino D, Kotzalidis G, Casale A, et al. Anabolic-androgenic Steroid use and Psychopathology in Athletes. A Systematic Review. Curr Neuropharmacol 2015;13:101-21. doi:10.2174/1570159X13666141210222725

18 Markser V, Currie A, McAllister-Williams RH. Mood disorders. In: Currie A, Owen B, eds. Sports Psychiatry. Oxford: : Oxford University Press 2016. 3151.

19 Reardon C, Creado S. Drug abuse in athletes. Subst Abuse Rehabil 2014;:95105. doi:10.2147/SAR.S53784

20 Bahrke MS. Psychological and Behavioral Effects of Anabolic -Androgenic 
Steroids. Int J Sport Exerc Psychol 2005;3:428-45.

doi:10.1080/1612197X.2005.10807316

21 Trenton AJ, Currier GW. Behavioural manifestations of anabolic steroid use. CNS Drugs 2005;19:571-95.http://www.ncbi.nlm.nih.gov/pubmed/15984895 (accessed 18 Mar 2018).

22 Morse ED. Substance Use in Athletes. In: Clinical Sports Psychiatry. Oxford: : John Wiley \& Sons 2013. 1-12. doi:10.1002/9781118404904.ch1

23 National Institute for Health and Care Excellence. Bipolar Disorder (update): the assessment and management of bipolar disorder in adults, children and young people in primary and secondary care. 2014.

24 Hirschfield RMA, Bowden CL, Gitlin MJ, et al. Treatment of Patients With Bipolar Disorder Second Edition. APA Pract Guidel 2010;:1-82.

doi:10.1176/appi.books.9780890423363.50051

25 Sylvia LG, Friedman ES, Kocsis $\mathrm{JH}$, et al. Association of exercise with quality of life and mood symptoms in a comparative effectiveness study of bipolar disorder. J Affect Disord 2013;151:722-7. doi:10.1016/j.jad.2013.07.031

26 Strohle A, Hofler M, Pfister $\mathrm{H}$, et al. Physical activity and prevalence and incidence of mental disorders in adolescents and young adults. Psychol Med 2007;37:1657-66. doi:10.1017/S003329170700089X

27 Wright K, Armstrong T, Taylor A, et al. 'It's a double edged sword': A qualitative analysis of the experiences of exercise amongst people with Bipolar Disorder. J Affect Disord 2012;136:634-42. doi:10.1016/j.jad.2011.10.017

28 Dudek D, Siwek M, Jaeschke R, et al. A web-based study of bipolarity and impulsivity in athletes engaging in extreme and high-risk sports. Acta Neuropsychiatr 2016;28:179-83. doi:10.1017/neu.2015.44

29 Duman $\mathrm{CH}$, Schlesinger L, Russell DS, et al. Voluntary exercise produces antidepressant and anxiolytic behavioral effects in mice. Brain Res 2008;1199:148-58. doi:10.1016/j.brainres.2007.12.047

30 Thomson D, Turner A, Lauder S, et al. A brief review of exercise, bipolar disorder, and mechanistic pathways. Front Psychol 2015;6:1-10. doi:10.3389/fpsyg.2015.00147

31 Depue RA, Slater JF, Wolfstetter-Kausch H, et al. A behavioral paradigm for identifying persons at risk for bipolar depressive disorder: a conceptual framework and five validation studies. J Abnorm Psychol 1981;90:381- 
437.http://www.ncbi.nlm.nih.gov/pubmed/7298991 (accessed 4 Jan 2019).

Urosević S, Abramson LY, Harmon-Jones E, et al. Dysregulation of the behavioral approach system (BAS) in bipolar spectrum disorders: review of theory and evidence. Clin Psychol Rev 2008;28:1188-205.

doi:10.1016/j.cpr.2008.04.004

33 van Os J, Linscott RJ, Myin-Germeys I, et al. A systematic review and metaanalysis of the psychosis continuum: evidence for a psychosis pronenesspersistence-impairment model of psychotic disorder. Psychol Med 2009;39:179. doi:10.1017/S0033291708003814

34 Ising HK, Veling W, Loewy RL, et al. The validity of the 16-item version of the Prodromal Questionnaire (PQ-16) to screen for ultra high risk of developing psychosis in the general help-seeking population. Schizophr Bull 2012;38:1288-96. doi:10.1093/schbul/sbs068

35 National Institute for Health and Care Excellence. Psychosis and schizophrenia in adults : prevention and management. 2014.

36 Lehman AF, Lieberman JA, Dixon LB, et al. Practice Guideline for the Treatment of Patients With Schizophrenia. 2nd ed. Washington DC: 2010. doi:http://dx.doi.org/10.1037/0003-066X.57.12.1052

37 Merikangas KR, Jin R, He J-P, et al. Prevalence and correlates of bipolar spectrum disorder in the world mental health survey initiative. Arch Gen Psychiatry 2011;68:241-51. doi:10.1001/archgenpsychiatry.2011.12

38 Goldner EM, Hsu L, Waraich P, et al. Prevalence and Incidence Studies of Schizophrenic Disorders: A Systematic Review of the Literature. Can J Psychiatry 2002;47:833-43. doi:10.1177/070674370204700904

39 Rice SM, Purcell R, De Silva S, et al. The Mental Health of Elite Athletes: A Narrative Systematic Review. Sport Med 2016;46:1333-53.

doi:10.1007/s40279-016-0492-2

40 Reardon CL. Psychiatric Comorbidities in Sports. Neurol Clin 2017;35:537-46. doi:10.1016/j.ncl.2017.03.007

41 Reardon CL, Factor RM. Sport Psychiatry: A systematic review of diagnosis and medical treatment of mental illness in athletes. Sport Med 2010;40:96180. doi:10.2165/11536580-000000000-00000

42 Ströhle A. Sports psychiatry: mental health and mental disorders in athletes and exercise treatment of mental disorders. Eur Arch Psychiatry Clin Neurosci 
2018;:1-14. doi:10.1007/s00406-018-0891-5

43 Favor Hamilton S, Tomlinson S. Fast girl : a life spent running from madness. 1st ed. Harper Collins 2016.

44 Rosa AR, Reinares M, Michalak EE, et al. Functional Impairment and Disability across Mood States in Bipolar Disorder. Value Heal 2010;13:984-8. doi:10.1111/j.1524-4733.2010.00768.x

45 Melo MCA, Daher EDF, Albuquerque SGC, et al. Exercise in bipolar patients: A systematic review. J Affect Disord 2016;198:32-8.

doi:10.1016/j.jad.2016.03.004

46 Iverson GL, Brooks BL, Langenecker SA, et al. Identifying a cognitive impairment subgroup in adults with mood disorders. J Affect Disord 2011;132:360-7. doi:10.1016/j.jad.2011.03.001

47 Robinson LJ, Thompson JM, Gallagher P, et al. A meta-analysis of cognitive deficits in euthymic patients with bipolar disorder. J Affect Disord 2006;93:10515. doi:10.1016/j.jad.2006.02.016

48 Bora E. Neurocognitive features in clinical subgroups of bipolar disorder: A meta-analysis. J Affect Disord 2018;229:125-34. doi:10.1016/j.jad.2017.12.057

49 Carvalho AF, Bortolato B, Miskowiak K, et al. Cognitive dysfunction in bipolar disorder and schizophrenia: a systematic review of meta-analyses. Neuropsychiatr Dis Treat 2015;11:3111. doi:10.2147/NDT.S76700

50 Berk M, Dandash O, Daglas R, et al. Neuroprotection after a first episode of mania: a randomized controlled maintenance trial comparing the effects of lithium and quetiapine on grey and white matter volume. Trans/ Psychiatry 2017;7:e1011. doi:10.1038/tp.2016.281

51 Green MF. What are the functional consequences of neurocognitive deficits in schizophrenia? Am J Psychiatry 1996;153:321-30. doi:10.1176/ajp.153.3.321

52 Rabinowitz J, Levine SZ, Garibaldi G, et al. Negative symptoms have greater impact on functioning than positive symptoms in schizophrenia: Analysis of CATIE data. Schizophr Res 2012;137:147-50. doi:10.1016/j.schres.2012.01.015

53 Joyce K, Thompson A, Marwaha S. Is treatment for bipolar disorder more effective earlier in illness course? A comprehensive literature review. Int J Bipolar Disord 2016;4:1-9. doi:10.1186/s40345-016-0060-6 
54 Penttilä M, Jaäskel̈ainen E, Hirvonen N, et al. Duration of untreated psychosis as predictor of long-term outcome in schizophrenia: Systematic review and meta-analysis. Br J Psychiatry 2014;205:88-94.

doi:10.1192/bjp.bp.113.127753

55 Berk M, Post R, Ratheesh A, et al. Staging in bipolar disorder: from theoretical framework to clinical utility. World Psychiatry 2017;16:236-44.

doi:10.1002/wps.20441

56 Fusar-Poli P, Borgwardt S, Bechdolf A, et al. The Psychosis High-Risk State; A Comprehensive State-of-the-Art Review Paolo. JAMA Psychiatry 2013;70:107-20. doi:10.1001/jamapsychiatry.2013.269

57 Liu C-C, Demjaha A. Antipsychotic Interventions in Prodromal Psychosis. CNS Drugs 2013;27:197-205. doi:10.1007/s40263-013-0046-1

58 Swann C, Telenta J, Draper G, et al. Youth sport as a context for supporting mental health: Adolescent male perspectives. Psychol Sport Exerc 2018;35:55-64. doi:10.1016/j.psychsport.2017.11.008

59 Firth J, Cotter J, Elliott R, et al. A systematic review and meta-analysis of exercise interventions in schizophrenia patients. Psychol Med 2015;45:134361. doi:10.1017/S0033291714003110

60 Dauwan M, Begemann MJH, Heringa SM, et al. Exercise Improves Clinical Symptoms, Quality of Life, Global Functioning, and Depression in Schizophrenia: A Systematic Review and Meta-analysis. Schizophr Bull 2016;42:588-99. doi:10.1093/schbul/sbv164

61 Carless D. Narrative, Identity, and Recovery from Serious Mental IIIness: A Life History of a Runner. Qual Res Psychol 2008;5:233-48. doi:10.1080/14780880701826101

62 Andresen R, Oades L, Caputi P. The Experience of Recovery from Schizophrenia: Towards an Empirically Validated Stage Model. Aust New Zeal J Psychiatry 2003;37:586-94. doi:10.1046/j.1440-1614.2003.01234.x

63 Currie A, Malik R. Exercise participation and mental health. In: Currie A, Owen B, eds. Sports Psychiatry. Oxford: : Oxford University Press 2016. 107-16.

64 Haukvik UK, Tamnes CK, Söderman E, et al. Neuroimaging hippocampal subfields in schizophrenia and bipolar disorder: A systematic review and metaanalysis. J Psychiatr Res 2018;104:217-26.

doi:10.1016/j.jpsychires.2018.08.012 
65 Pajonk F-G, Wobrock T, Gruber O, et al. Hippocampal Plasticity in Response to Exercise in Schizophrenia. Arch Gen Psychiatry 2010;67:133-

43.https://pdfs.semanticscholar.org/0c49/2b8dcac2f03baff652a2df1c7c1efb50 06a9.pdf (accessed 28 Mar 2018).

66 Scheewe TW, van Haren NE, Sarkisyan G, et al. Exercise therapy, cardiorespiratory fitness and their effect on brain volumes: A randomised controlled trial in patients with schizophrenia and healthy controls. Eur Neuropsychopharmacol 2013;23:675-85.

doi:10.1016/j.euroneuro.2012.08.008

67 Brand S, Gerber M, Beck J, et al. High Exercise Levels Are Related to Favorable Sleep Patterns and Psychological Functioning in Adolescents: A Comparison of Athletes and Controls. J Adolesc Heal 2010;46:133-41. doi:10.1016/j.jadohealth.2009.06.018

68 Wulff K, Dijk D-J, Middleton B, et al. Sleep and circadian rhythm disruption in schizophrenia. Br J Psychiatry 2012;200:308-16.

doi:10.1192/bjp.bp.111.096321

69 Bradley AJ, Webb-Mitchell R, Hazu A, et al. Sleep and circadian rhythm disturbance in bipolar disorder. Psychol Med 2017;47:1678-89. doi:10.1017/S0033291717000186

70 Colom F, Vieta E, Reinares M, et al. Psychoeducation efficacy in bipolar disorders: beyond compliance enhancement. J Clin Psychiatry 2003;64:11015.http://www.ncbi.nlm.nih.gov/pubmed/14628987 (accessed 31 Jan 2019).

71 Frank E, Swartz HA, Kupfer DJ. Interpersonal and social rhythm therapy: managing the chaos of bipolar disorder. Biol Psychiatry 2000;48:593604.http://www.ncbi.nlm.nih.gov/pubmed/11018230 (accessed 10 Oct 2018).

72 Frank E, Soreca I, Schwartz H, et al. The Role of Interpersonal and Social Rhythm Therapy in Improving Occupational Functioning in Patients With Bipolar I Disorder. Am J Psychiatry 2008;165:1559-65. doi:1doi:10.1176/appi.ajp.2008.07121953

73 Johnston A, McAllister-Williams RH. Psychotropic Drug Prescribing. In: Currie A, Owen B, eds. Sports Psychiatry. Oxford: : Oxford University Press 2016. 133-43.

74 Reardon CL. The sports psychiatrist and psychiatric medication. Int Rev Psychiatry 2016;28:606-13. doi:10.1080/09540261.2016.1190691 
75 Geddes JR, Calabrese JR, Goodwin GM. Lamotrigine for treatment of bipolar depression: independent meta-analysis and meta-regression of individual patient data from five randomised trials. Br J Psychiatry 2009;194:4-9. doi:10.1192/bjp.bp.107.048504

76 van der Loos MLM, Mulder PGH, Hartong EGTM, et al. Efficacy and safety of lamotrigine as add-on treatment to lithium in bipolar depression: a multicenter, double-blind, placebo-controlled trial. J Clin Psychiatry 2009;70:22331.http://www.ncbi.nlm.nih.gov/pubmed/19200421 (accessed 24 Oct 2018).

77 Sidor MM, MacQueen GM. Antidepressants for the Acute Treatment of Bipolar Depression. J Clin Psychiatry 2011;72:156-67. doi:10.4088/JCP.09r05385gre

78 Post RM, Altshuler LL, Leverich GS, et al. Mood switch in bipolar depression: comparison of adjunctive venlafaxine, bupropion and sertraline. $\mathrm{Br} \mathrm{J}$ Psychiatry 2006;189:124-31. doi:10.1192/bjp.bp.105.013045

79 Peet M. Induction of mania with selective serotonin re-uptake inhibitors and tricyclic antidepressants. Br J Psychiatry J Ment Sci 1994;164:549_ 50.http://www.ncbi.nlm.nih.gov/pubmed/8038948 (accessed 24 Oct 2018).

80 Weisler RH, Nolen WA, Neijber A, et al. Continuation of Quetiapine Versus Switching to Placebo or Lithium for Maintenance Treatment of Bipolar I Disorder. J Clin Psychiatry 2011;72:1452-64. doi:10.4088/JCP.11m06878

81 Reardon CL, Creado S. Psychiatric medication preferences of sports psychiatrists. Physician Sport Med 2016;44:397-402. doi:10.1080/00913847.2016.1216719

82 Jefferson JW, Greist JH, Clagnaz PJ, et al. Effect of strenuous exercise on serum lithium level in man. Am J Psychiatry 1982;139:1593-5. doi:10.1176/ajp.139.12.1593

83 Miller EB, Pain RW, Skripal PJ. Sweat lithium in manic-depression. $\mathrm{Br} \mathrm{J}$ Psychiatry 1978;133:477-8.http://www.ncbi.nlm.nih.gov/pubmed/728699 (accessed 11 Jul 2018).

84 Beach SR, Celano CM, Noseworthy PA, et al. QTc Prolongation, Torsades de Pointes, and Psychotropic Medications. Psychosomatics 2013;54:1-13. doi:10.1016/j.psym.2012.11.001

85 Barnes T, Schizophrenia Consensus Group of British Association of Psychopharmacology. Evidence-based guidelines for the pharmacological treatment of schizophrenia: recommendations from the British Association for 
Psychopharmacology. J Pharmacol 2011;25:567-620.

doi:10.1177/0269881110391123

86 Kaufman KR, Campeas M, Coluccio M, et al. Bipolar disorders and comorbid conditions - Ethical considerations in sports. Apunt Med l'Esport 2018;53:5561. doi:10.1016/j.apunts.2017.10.001 